\title{
Seismic Wavefields in the Deep Seafloor Area from a Submarine Landslide Source
}

\author{
Takeshi Nakamura, ${ }^{1}$ Hiroshi Takenaka, ${ }^{2,4}$ Taro Okamoto, ${ }^{3}$ and Yoshiyuki Kaneda ${ }^{1}$
}

\begin{abstract}
We use the finite difference method to simulate seismic wavefields at broadband land and seafloor stations for a given terrestrial landslide source, where the seafloor stations are located at water depths of 1,900-4,300 m. Our simulation results for the landslide source explain observations well at the seafloor stations for a frequency range of $0.05-0.1 \mathrm{~Hz}$. Assuming the epicenter to be located in the vicinity of a large submarine slump, we also model wavefields at the stations for a submarine landslide source. We detect propagation of the Airy phase with an apparent velocity of $0.7 \mathrm{~km} / \mathrm{s}$ in association with the seawater layer and an accretionary prism for the vertical component of waveforms at the seafloor stations. This later phase is not detected when the structural model does not consider seawater. For the model incorporating the seawater, the amplitude of the vertical component at seafloor stations can be up to four times that for the model that excludes seawater; we attribute this to the effects of the seawater layer on the wavefields. We also find that the amplification of the waveform depends not only on the presence of the seawater layer but also on the thickness of the accretionary prism, indicating low amplitudes at the land stations and at seafloor stations located near the trough but high amplitudes at other stations, particularly those located above the thick prism off the trough. Ignoring these characteristic structures in the oceanic area and simply calculating the wavefields using the same structural model used for land areas would result in erroneous estimates of the size of the submarine landslide and the mechanisms underlying its generation. Our results highlight the importance of adopting a structural model that incorporates the $3 \mathrm{D}$ accretionary prism and seawater layer into the simulation in order to precisely evaluate seismic wavefields in seafloor areas.
\end{abstract}

Key words: DONET, landslide, seismic wave propagation, finite difference method, seafloor observation, tonankai area.

1 Earthquake and Tsunami Research Project for Disaster Prevention, Japan Agency for Marine-Earth Science and Technology, 3173-25 Showa-machi, Kanazawa-ku Yokohama 236-0001, Japan. E-mail: t_nakamura@jamstec.go.jp

2 Department of Earth and Planetary Sciences, Kyushu University, 6-10-1 Hakozaki, Higashi-ku 812-8581, Japan.

3 Department of Earth and Planetary Sciences, Tokyo Institute of Technology, 2-12-1 Ookayama, Meguro-ku Tokyo 152-8551, Japan.

4 Present Address: Department of Earth Sciences, Okayama University, 3-1-1 Tsushima-Naka, Kita-ku Okayama 700-8530, Japan.

\section{Introduction}

Submarine landslides are gravitational phenomena that occur at the seafloor in regions of steep slope. Several observational and simulation studies (primarily bathymetric surveys and tsunami studies) have shown that submarine landslides are most likely to be triggered during large earthquakes. Moreover, generation of submarine landslides can cause (or at least contribute to) the amplification of tsunamis and can damage infrastructure such as submarine cables and water pipes. HeEzen and Ewing (1952) attributed the breaking of transoceanic telegraph cables connecting North America to Europe to submarine landslides and turbidity currents that occurred around $13 \mathrm{~h}$ after the 1929 Grand Banks, Canada, earthquake (M 7.2). Similarly, TAPPIN et al. (2001) found evidence for submarine landslides related to the 1998 Papua New Guinea earthquake (M 7.0) based on bathymetric surveys, and presented evidence to suggest that these landslides were associated with the tsunami source. Moreover, investigation of seafloor topography before and after the 2011 Tohoku earthquake (M 9.0) in Japan produced evidence of a local submarine landslide adjacent to the trench axis (FuJIwara et al. 2011). KaWAMURA et al. (2012) proposed large horizontal displacements due to submarine landsliding as a possible cause for the tsunami that struck Japan in 2011. BАВA et al. (2012) found a clear difference in seafloor topography before and after the 2009 Suruga Bay, Japan, earthquake (M 6.4), which they interpreted to be associated with a submarine landslide on the basis of bathymetric surveys. Moreover, they demonstrated that numerical simulations assuming this change in seafloor topography associated with the submarine landslide were better able to explain the tsunami observed in coastal areas than those based on fault motion alone. 
Terrestrial landslides have been studied extensively by adopting geomorphological, geological, and geophysical approaches. In particular, previous studies have found evidence for diverse sources of terrestrial landslides, including volcanic activity, extreme rainfall, melting snow, and rising groundwater levels; however, these may be different to the factors that induce submarine landslides. KANAMORI and Given (1982) analyzed low-frequency seismic signals associated with a terrestrial landslide related to the 1980 Mount St. Helens eruption in Washington, finding a horizontal single force to be the source of seismic radiation. Similarly, LA Rocca et al. (2004) analyzed seismic signals associated with terrestrial landslides and tsunamis that occurred at the Stromboli volcano in Italy, and Yamada et al. (2012) analyzed high-frequency seismic signals to determine the source location of terrestrial landslides due to a typhoon in southwest Japan. Moreover, GuzzeTti et al. (2002) investigated terrestrial landslides caused by rapid melting of snow in Italy in 1997, proposing a scaling model for the frequency-size distribution of such landslides.

One of the prominent features typically found in seismic signals from landslides is a long-lasting motion involving low-frequency $(<0.1 \mathrm{~Hz})$ signals. Kanamori and Given (1982) found that observed waves from terrestrial landslides at great distances are rich in low-frequency components compared with those of ordinary earthquakes. Similarly, CHEN et al. (2013) investigated differences in spectrograms between landslides and local and teleseismic events and found much of the prolonged seismic energy associated with the landslides to lie within a relatively narrow low-frequency band. Such long-lasting low-frequency components have been interpreted as a result of predominantly gravitational fall of a large rock mass around the free surface, which is often expressed seismologically as a single force with long duration. Thus, based on the observation of this unique feature in seismic data, it should be possible to detect seismic signals associated with terrestrial landslides and distinguish them from those of ordinary earthquakes.

Few studies to date have investigated seismic signals from submarine landslides occurring at the deep seafloor, likely owing to the rare occurrence of such landslides, which depends primarily on the frequency of occurrence of large suboceanic earthquakes. Moreover, few seismic stations are located in the oceanic areas in which such events occur. Furthermore, it is often difficult to ascertain whether a submarine landslide has really occurred because ship-based topographic surveys after earthquake events require immense time and effort. Therefore, analysis of seismic signals received at land stations is currently one of the most practical and rapid means of detecting submarine landslides without a field survey. For example, Lin et al. (2010) detected submarine landslides in Taiwan and analyzed the mechanisms underlying these landslides by conducting waveform inversion for low-frequency seismic data observed by the dense broadband seismic network covering land areas. However, care must be taken when identifying seismic signals associated with submarine landslides in cases involving limited observation data obtained from a limited number of land stations that are located far from the associated epicenter. Some unusual suboceanic events such as submarine volcanic activity, very low-frequency (VLF) earthquakes, and tsunami earthquakes typically generate long-lasting low-frequency seismic signals (e.g., KANAMORI, 1972; SugioKa et al. 2012), which may introduce difficulties in separating the seismic signals associated with submarine landslides from those related to unusual suboceanic events. However, use of seafloor broadband seismic stations near sources should improve detection of submarine landslide signals by allowing direct observation of suboceanic phenomena in oceanic areas. Additionally, performing seismic simulations for such phenomena and comparing the simulation results with seafloor observations will allow verification of the occurrence of submarine landslides.

Recently, we deployed seafloor stations with a dense array, namely DONET (Dense Oceanfloor Network System for Earthquakes and Tsunamis), in water depths of 1,900-4,400 $\mathrm{m}$ near the Nankai trough in southwest Japan (Fig.1) (KANEDA et al., 2010; Kawaguchi et al. 2011). The network system consists of 20 dense array stations in total. Each station has strong motion and broadband seismic 
sensors and pressure gauges to observe broadband signals for seismic events, geodetic deformations, and tsunamis. We believe that this network system is also useful in the detection and analysis of signals from submarine landslides because the network can observe signals directly at the seafloor. The stations are distributed throughout an area that spans $50 \mathrm{~km} \times 100 \mathrm{~km}$ (along and perpendicular to the trench axis, respectively), which is comparable to or greater than the density of the associated land station network.

In this study, we investigate seismic wavefields at DONET seafloor stations for a terrestrial landslide and a submarine landslide based on finite difference simulation. Our finite difference method can incorporate a three-dimensional (3D) structural model that incorporates a seawater layer and seafloor topography into the simulation. The simulation for DONET will contribute to our analysis and interpretation of recordings for such submarine events and will enhance our understanding of wavefields at the deep seafloor. Additionally, we compare the simulated waveforms for cases with and without the seawater layer in the structural model; then, we discuss the possible causes underlying any waveform differences and the effects of the seawater layer on the seismic wavefields.

\section{Simulation Method}

We employ the heterogeneity, oceanic layer, and topography (HOT)-FDM scheme adopted by NAKAMURA et al. (2012) to simulate seismic wave propagation in land and oceanic areas. This scheme can incorporate heterogeneities, a seawater layer, and topography into the finite difference simulation. Moreover, in contrast to conventional FDM schemes, this scheme can also implement the fluid-solid boundary correctly for the ocean surface, seafloor, and land surface (free surface) (Окамото and TакеNAKA 2005; TAKENAKA et al., 2009). Thus, calculation errors due to unsatisfactory representation of fluidsolid boundary conditions can be avoided (NAKAMURA et al., 2011). Accordingly, we believe that the HOTFDM scheme is appropriate for simulation of submarine sources at the seafloor.

\section{Source Model used in Simulations}

In the first simulation, we calculate seismic wavefields detected at land and seafloor stations from a terrestrial landslide (simulation 1) that occurred inland to demonstrate that our HOT-FDM scheme adequately reproduces observations at the stations. The landslide we simulate was caused by a typhoon passing over the Kii peninsula in southwest Japan on September 4, 2011. In our simulation, we use the source location (longitude, latitude = $135.715^{\circ}, 34.133^{\circ}$ ) described by YAMADA et al. (2012) and the source time function derived from the waveform inversion conducted by YAMADA et al. (2013). The locations of the landslide and the stations used in our simulation are presented in Fig. 1. We also present a detailed topographic map in Fig. 1b; this map was created using topography data obtained from a $5 \mathrm{~m}$ mesh provided by the Geospatial Information Authority of Japan (GSI). Chigira et al. (2012) estimated a landslide area of $4.2 \times 10^{5} \mathrm{~m}^{2}$ and a sliding volume of $8.0 \times 10^{6} \mathrm{~m}^{3}$ by comparing topographic data obtained before and after the event. The source time function of a single force suggests a maximum force of $5.5 \times 10^{10} \mathrm{~N}$, a duration of 50-70 s, and a maximum sliding speed of $28 \mathrm{~m} / \mathrm{s}$ (YAmADA et al. 2012, 2013). We extract the part representing the appropriate duration from their original function data and apply a cosine taper of $5 \mathrm{~s}$ to the beginning and end to produce a smooth function. Figure 2 illustrates the source time function used in our simulation. Such long source duration could be caused by a landslide occurring with the speed of a gravitational fall rather than an elastic rupture. Furthermore, the single force acts in the opposite direction to the sliding flow, in agreement with previous seismological studies (e.g., KanAmori and Given, 1982; EISSLeR and KanAmori 1987; Dahlen, 1993; Fukao, 1995).

Next, we simulate the wavefields from a submarine landslide (simulation 2), assuming that future landslides may occur on the steeply sloping seafloor off Cape Shiono (Fig. 1), where a large slump can be seen clearly on maps of seafloor topography. We also present a detailed topographic map in Fig. 1c; this map is based on merging bathymetric survey data observed along cruise tracks of research vessels. We 
(a)

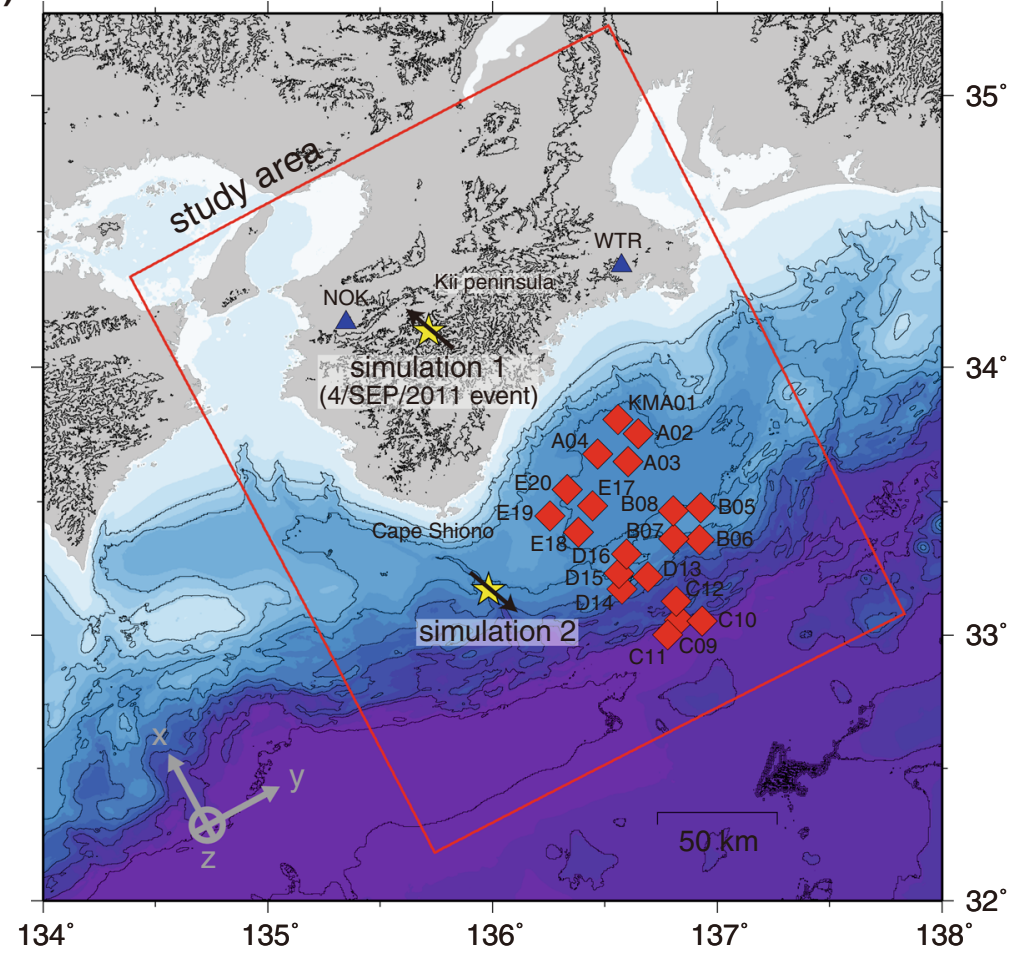

(b) topography around terrestrial landslide (simulation 1)

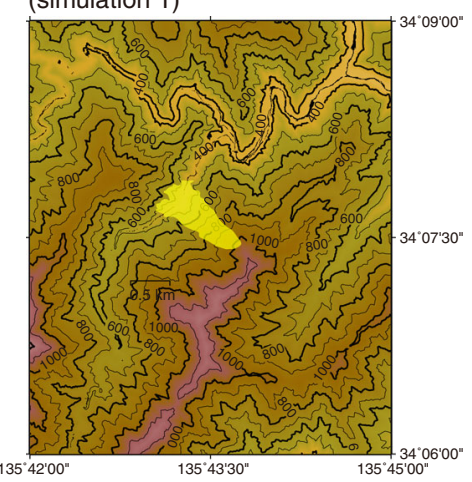

(c) topography around submarine landslide (simulation 2)

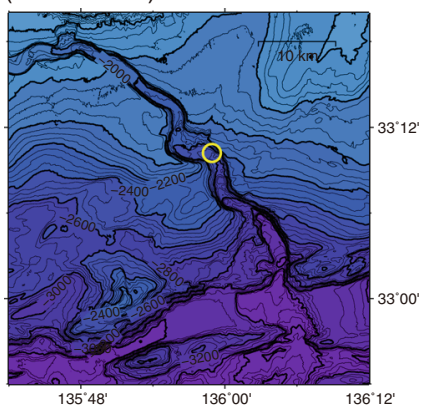

Figure 1

a Location of sources and stations used in our simulation. We simulate two cases: a terrestrial landslide source (simulation 1) and a submarine landslide source (simulation 2), indicated by yellow stars. The sliding direction is indicated by black arrows. Blue triangles and red diamonds indicate the locations of land stations of F-net and seafloor stations of DONET, respectively. A red rectangle indicates the area of our simulation. Black contour lines indicate land and seafloor topography at intervals of $500 \mathrm{~m}$. The Cartesian coordinate system used in this study is also shown. b Detailed topographic map of $5 \mathrm{~m}$ mesh data around the terrestrial landslide source. Yellow portion indicates the area of the 2011 landslide, obtained by digitizing the results of CHIGIRA (2012). c Detailed topographic map around the submarine landslide source, obtained by merging bathymetric survey data observed along cruise tracks of research vessels. A yellow circle indicates the area of the submarine landslide used in our simulation

assume the epicenter to be located in the middle of the slump (longitude $135.982^{\circ}$, latitude $33.170^{\circ}$ ). Because seismometer observations of submarine landslides are rare and the source mechanisms of such landslides remain poorly understood, we here use the source time function for landslide sources presented by YAMADA et al. (2013). We believe the use of this function to be appropriate because the source time function of the submarine landslide could exhibit a sinusoidal shape (HASEgawa and KANAMORI 1987), similar to that of the terrestrial landslide. As discussed above, the maximum sliding speed of $28 \mathrm{~m} / \mathrm{s}$ for the terrestrial landslide is also considered to be appropriate based on other studies of submarine landslides. Based on tsunami simulations, BONDEVIK et al. (2005) suggested a maximum sliding speed of approximately $25-30 \mathrm{~m} / \mathrm{s}$ for the Storegga slide, one of the largest known submarine landslides. Other studies have suggested speeds of a few tens of meters per second at the seafloor, e.g., for the Nuuanu landslide off the Hawaiian Islands (WARD, 2001) and the 1998 Papua New Guinea earthquake (HeINRICH et al. 2001). In our simulation, we also assume that the submarine landslide is sliding toward the southeast (black arrow in Fig. 1), which is consistent with the slumping flow indicated by the topographic map. Since the sliding or force direction is opposite to that of the terrestrial landslide in the Kii peninsula, we 


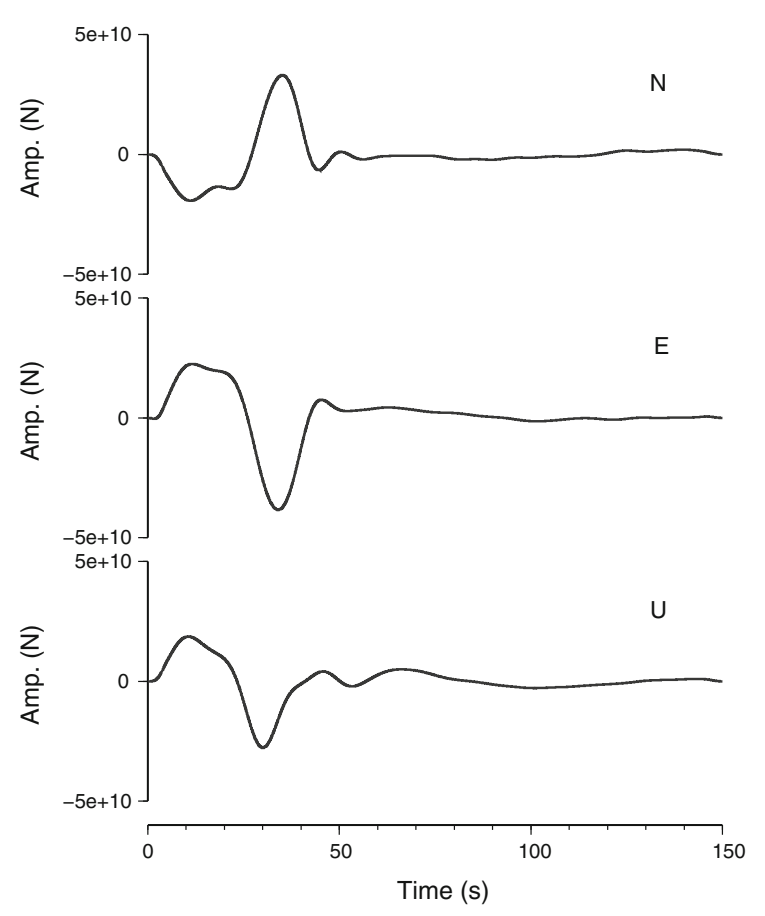

Figure 2

Source time function of the terrestrial landslide (simulation 1 in Fig. 1) used in our simulation. The function is based on the results of the waveform inversion by YAMADA (2013). We extract the part representing the main duration from their original function data and apply a cosine taper of $5 \mathrm{~s}$ to the beginning and end to produce a smooth function. We use the same function for the submarine landslide source (simulation 2 in Fig. 2), but reverse the sign of the horizontal component based on the assumption that the force is acting in the opposite direction to that of the terrestrial landslide source

reverse the sign of the horizontal component of the function presented by YAMADA et al. (2013) and use this for the simulation.

\section{Subsurface Structural Model used in Simulations}

We use a structural model, the Nankai Rendo Project 2011 model (CITAK et al. 2012), that includes subducting plate, oceanic mantle, and accretionary prism components. This model defines the 3D shape of each layer, which is determined by compiling the results of reflection and refraction seismic surveys (e.g., NaKanishi et al. 2002), Japan Meteorological Agency (JMA) hypocenter distributions, and receiver function analysis (e.g., Sнiом et al., 2004). We also use the JMA 2001 velocity model (UENo et al. 2002) for the structure of the continental crust. The density used is that determined based on an empirical relationship as a function of $V p$ given by BROCHER (2005). For land and ocean bottom topography, we use 50 and 500-m mesh data provided by the GSI and the Japan Oceanographic Data Center (JODC), respectively. We implement a seawater layer with $V \mathrm{p}=1.5 \mathrm{~km} / \mathrm{s}$, $V \mathrm{~s}=0.0 \mathrm{~km} / \mathrm{s}$, and $\rho=1.05 \mathrm{~g} / \mathrm{cm}^{3}$; we also incorporate an air layer with $V \mathrm{p}=V \mathrm{~s}=0.0 \mathrm{~km} / \mathrm{s}$ to incorporate the effect of land topography (TAKENAKA et al. 2009). Figure 3 illustrates the structural model for $V \mathrm{p}$ used in our simulation. The minimum velocities of $V p$ and $V s$ are 2.0 and $1.0 \mathrm{~km} / \mathrm{s}$, respectively, in the shallowest layer in the accretionary prism.

The computational domain in this study covers an area of $270 \mathrm{~km} \times 220 \mathrm{~km}$ in and around the sources of the terrestrial and submarine landslides sources and extends to a depth of $94 \mathrm{~km}$. The spatial and temporal grid spacings are $0.2 \mathrm{~km}$ and $0.01 \mathrm{~s}$, respectively. We divide the computational domain into subregions, which allows us to perform efficient parallel computation for a large number of grids using existing message passing interface (MPI) libraries. The computational time and total memory requirement for 25,000 time steps (corresponding to $250.0 \mathrm{~s}$ ) using Xeon 2.6-GHz processors with a 1,024-core SGI ICE $X$ cluster are approximately $15.6 \mathrm{~h}$ and $633 \mathrm{~GB}$, respectively. We avoid artificial reflections from the sides and bottom of the computational domain by implementing convolutional perfectly matched layers (PMLs; e.g., DrossaerT and GianNopoulos 2007) in our code.

\section{Results and Discussion}

\subsection{Terrestrial Landslide Simulation}

We compare the simulation results for the terrestrial landslide source (simulation 1 in Fig. 1) with the observations obtained at land stations of F-net and seafloor stations of DONET in Fig. 4. The waveforms are converted to radial, transverse, and vertical components using sensor azimuth (NAKANO et al. 2012) and back azimuth to the source epicenter. We show only the vertical component for the 


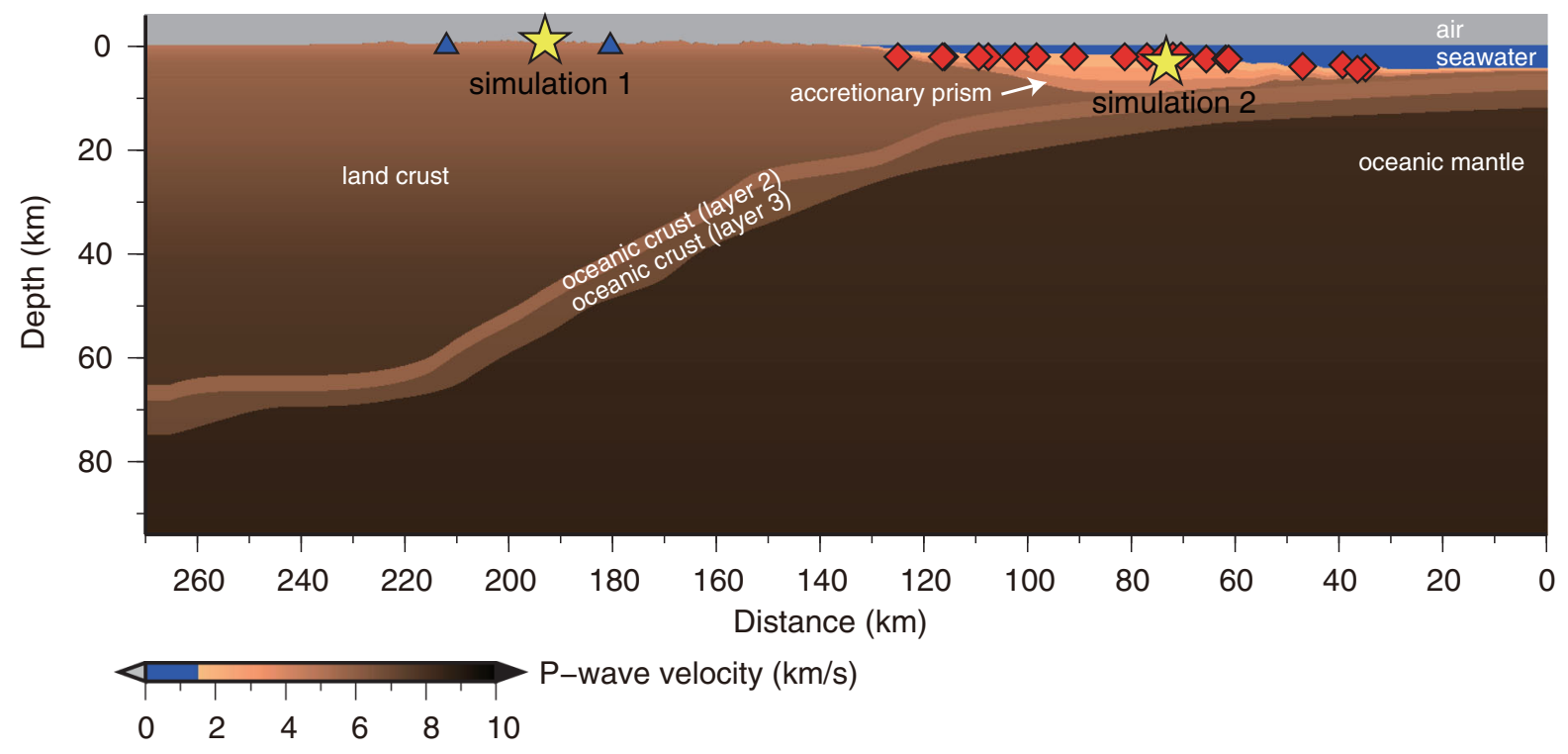

Figure 3

Cross-sectional representation of the structural model used in our simulation. The color scale indicates $P$-wave velocity. The cross section is based on the $x-z$ plane through the landslide source epicenter

observations at stations $\mathrm{KMC} 10$ and $\mathrm{KMC} 11$ of DONET because extraordinary observation noise was present in the horizontal component owing to the low coupling with ground sites. We apply an appropriate time shift for the synthetic waveform for all stations to match the main phases of the observed waveform in Fig. 4, since the origin time of the landslide source has been poorly determined owing to noise detected around the time of onset of body waves in the observation. We estimate the shifting time based on the time difference between the observed and synthetic waveforms of the main phases at station NOK of F-net, which is located near the source. The waveforms represent particle velocity $(\mathrm{cm} / \mathrm{s})$ that is band-pass filtered in the frequency range $0.05-0.1 \mathrm{~Hz}$. For the upper corner frequency of $0.1 \mathrm{~Hz}$ and grid spacing of $0.2 \mathrm{~km}$ used in our simulation, the model has more than 50 grid points per minimum shear wavelength in solid media. Then, we include many more grid points than would be included under standard sampling conditions for the fourth-order accurate finite-difference scheme, allowing us to suppress the numerical dispersion (ALFORD et al. 1974; Moczo et al. 2000). By applying the corner frequency of $0.1 \mathrm{~Hz}$, we can also suppress contamination of waveforms observed at seafloor stations by high-frequency noise, which results from local microseisms (e.g., WebB 1998; YANG et al. 2012), and the high ground and underwater noise levels generated by the approach of the typhoon itself.

The observed waveforms at land stations NOK and WTR exhibit long-duration seismic motions of more than $60 \mathrm{~s}$, which is significantly longer than the waveforms recorded from local seismic events. This suggests that the source process involves a relatively slow rise time due to a gravitational fall at the time of the event. We find the same features in the waveforms observed at the seafloor stations of DONET in the frequency range $0.05-0.1 \mathrm{~Hz}$. Moreover, the synthetic waveforms closely reproduce the features of the observed waveforms in terms of the arrival times of the main phases (i.e., those with the largest amplitudes) and the waveform as a whole at the land and seafloor stations in Fig. 4. However, the synthetic waveforms underestimate the amplitude at most of the seafloor stations. For example, the maximum amplitudes of the radial component of the synthetic and observed waveforms at station KMA01 are $6.37 \times 10^{-5}$ and $1.56 \times 10^{-4} \mathrm{~cm} / \mathrm{s}$, respectively; that is, the observed amplitude is around two and a half times the synthetic amplitude. This difference 
(a) simulation 1 results (F-net land stations)
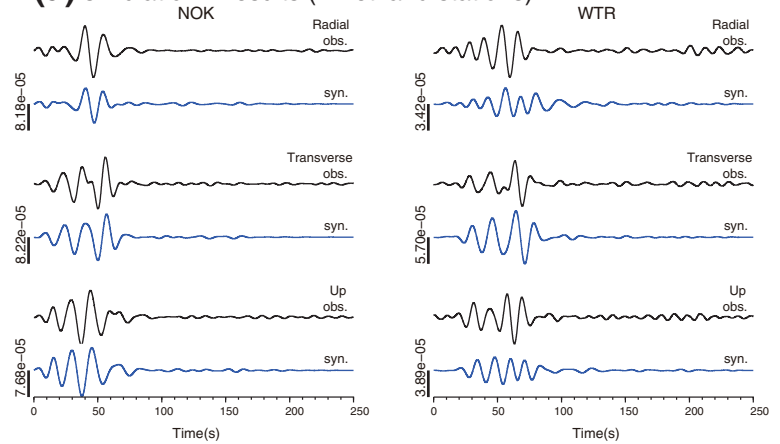

(b) simulation 1 results (DONET seafloor stations)

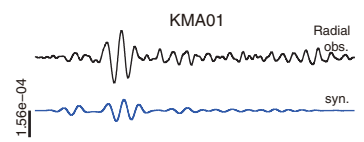

Transverse
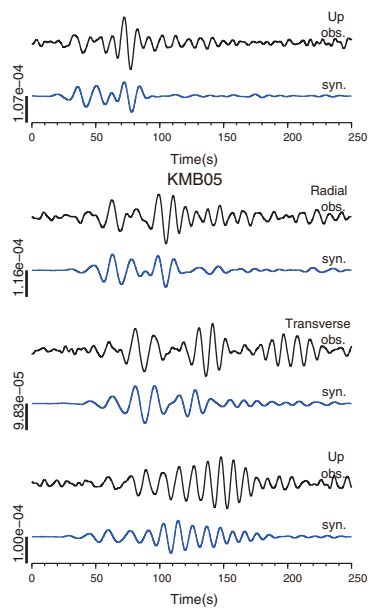
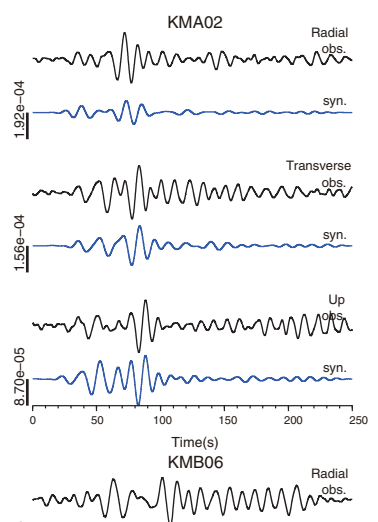

离

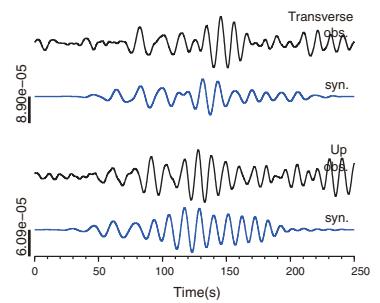

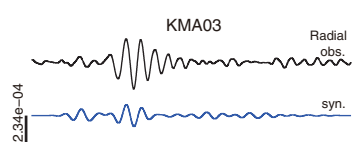

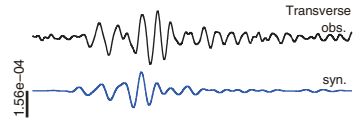

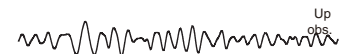

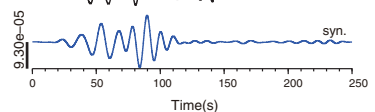
KMBO7
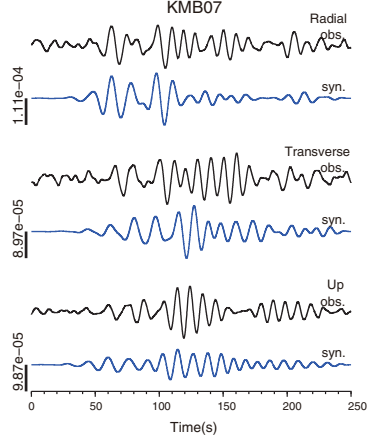
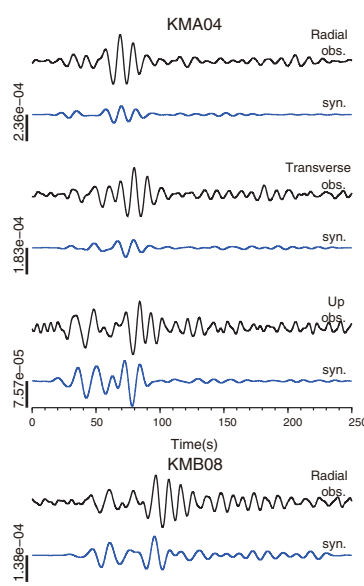

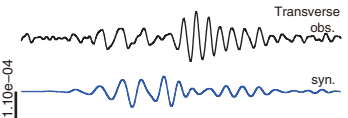

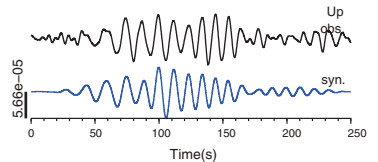

Figure 4

Simulation results for the terrestrial landslide source (simulation 1 in Fig. 1), displayed with observations. Black and blue lines indicate observed and synthetic waveforms (velocity, $\mathrm{cm} / \mathrm{s}$ ), respectively. Upper, middle, and lower traces for each station represent the radial, transverse, and vertical components, respectively. The amplitude is normalized for each component with respect to the larger of the observed and synthetic waveforms. a Waveforms at land stations of F-net. b Waveforms at seafloor stations of DONET. We show only the vertical component for the observations at stations $\mathrm{KMC} 10$ and $\mathrm{KMC} 11$ of DONET owing to observation noise in the horizontal component due to the low coupling with the ground site

may arise from the fact that the source time function is estimated using only land station data and assuming a $1 \mathrm{D}$ velocity structure, without using seafloor data and considering subsurface 3D heterogeneities, including the seawater layer and topography in the source analysis. The difference may also arise as a result of the effects of the shallow (i.e., near the seafloor) low-velocity structure on the seismic wavefield. We do not incorporate any low-velocity layers of less than $V \mathrm{~s}=1.0 \mathrm{~km} / \mathrm{s}$ around the seafloor or 
(b) simulation 1 results (DONET seafloor stations)

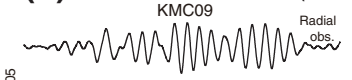$$
\text { 㖥 }
$$

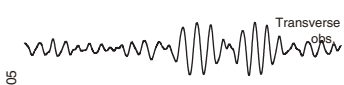

这

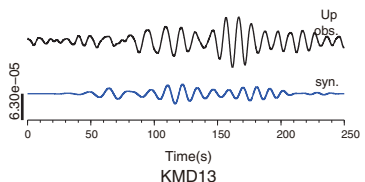

mWV M

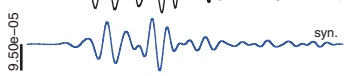
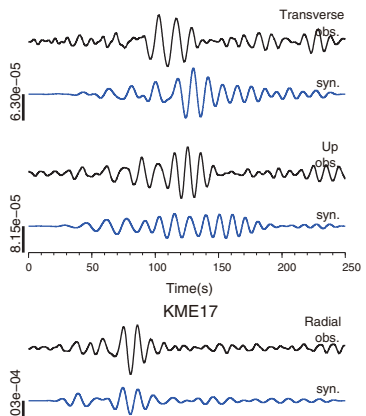

案

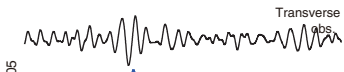
:

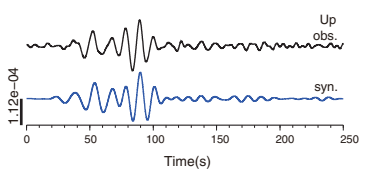

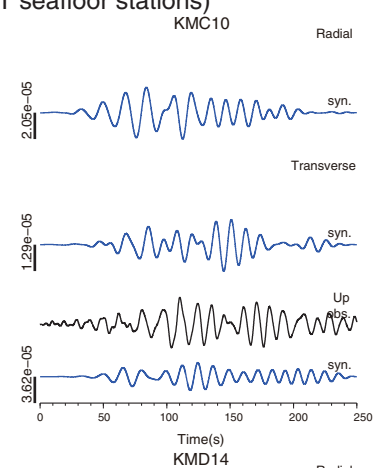

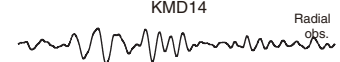
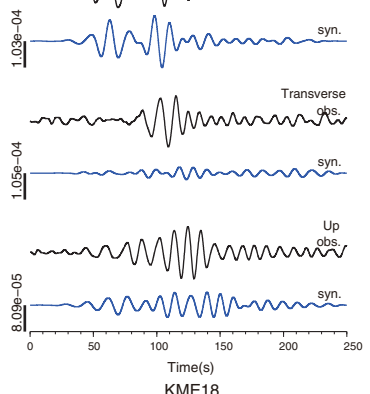

KME18

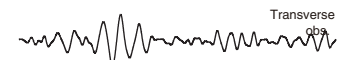

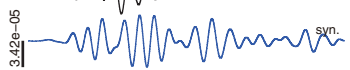

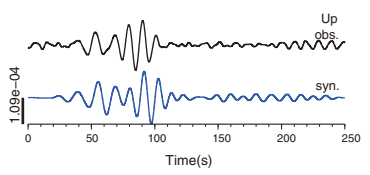

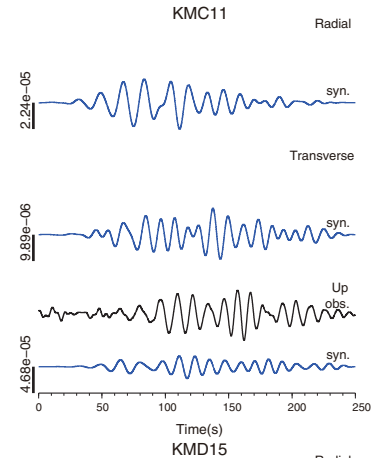

m WWMUnm

Wharmmm
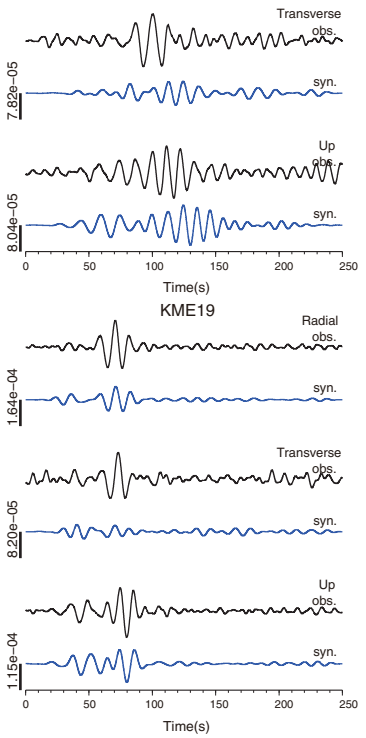

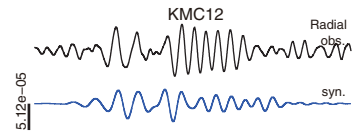

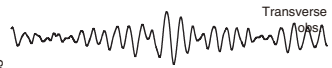
总

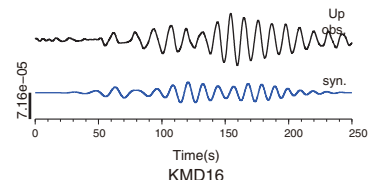

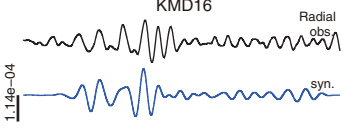
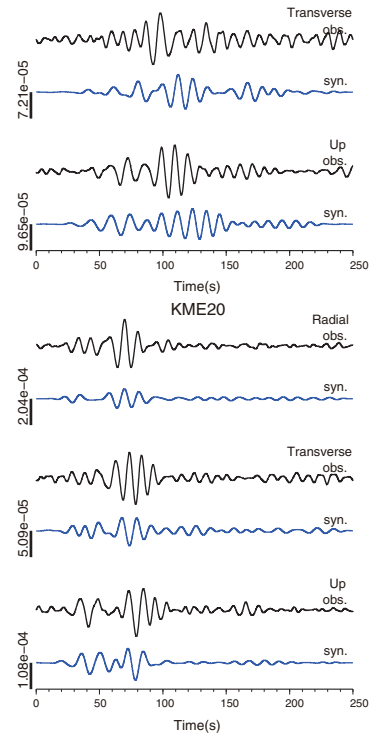

Figure 4

continued

incorporate local site effects immediately below the station into our simulation because we have adopted a spatial grid size of $0.2 \mathrm{~km}$. Furthermore, we do not incorporate any models to describe very shallow structures, particularly with regard to $S$-wave velocities derived from seismic survey data using an explosion source or from the limited number of core sample data at the seafloor. We believe that incorporating such information from source and structural models could lead to underestimation of the observed amplitude.

We examine the spatial distribution of the waveform amplitude among the stations and illustrate the maximum amplitude of each component for the synthetic and observed waveforms at the stations in Fig. 5. The systematic underestimation of the synthetic waveform is evident at the seafloor stations (Fig. 5), which may imply that the underestimation can be improved to some extent by modifying the source time function and structure. It is also clear from Fig. 5 that NOK and WTR of F-net (land stations) and KMC09-KMC12 of DONET (seafloor stations) exhibit lower amplitudes than other stations for both synthetic and observed waveforms. The reason for this will be discussed in Sect. 5.3. 


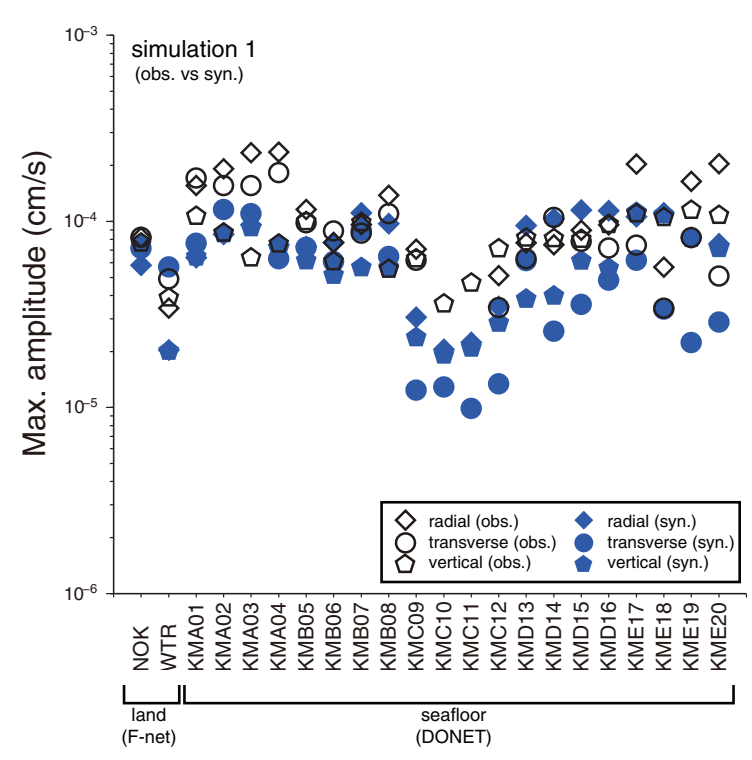

Figure 5

Comparison of the maximum amplitude of the observed and synthetic waveforms between stations. Open diamonds, circles, and pentagons indicate radial, transverse, and vertical components of the observed waveforms, respectively. Solid diamonds, circles, and pentagons indicate radial, transverse, and vertical components of the synthetic waveforms, respectively. It should be noted that the maximum amplitude is relatively small and independent of epicentral distance at land stations NOK and WTR of F-net and seafloor stations KMC09-KMC12 of DONET

\subsection{Submarine Landslide Simulation}

Our terrestrial landslide source simulation results explain well the overall features of the observed waveforms. In this section, we present the simulation results for the submarine landslide source (simulation 2 in Fig. 1).

The synthetic waveforms are represented by blue lines in Fig. 6 and indicate long-duration seismic motions similar to those found for the terrestrial landslide source as described in Sect. 5.1. The duration of these motions exceeds $100 \mathrm{~s}$ at several stations far from the submarine source (e.g., KMA01 of DONET), and these motions are similar to the reverberation of seismic waves. At DONET stations KMB05-KMB08, KMC09-KMC12, and KMD13KMD16, we find an isolated later phase in the vertical component. For example, the later phase is most distinct during 150-240 s of the vertical component of the synthetic waveform at station KMB05. This phase is a Rayleigh wave with very slow group velocity, sometimes less than the speed of $P$ waves in seawater $(1.5 \mathrm{~km} / \mathrm{s})$, and is strongly associated with the seawater layer and subsurface solid layers. The propagation speed and dominant frequency of this phase can be estimated from the group velocity curve, which depends considerably on the thickness of the seawater layer and the velocity structure of the subsurface solid layers. The phase exhibits large amplitudes at stations at local maxima or minima of the dispersion curve owing to the almost simultaneous arrival of waves from a range of frequencies. PEKERIS (1948) referred to this prominent part of the waveform as the Airy phase. Moreover, PREss et al. (1950) summarized the phase and group velocity curves for a structure consisting of a liquid layer resting upon a solid layer of infinite thickness. In the case of the specific structure illustrated in their study, $\alpha_{1}=1.52 \mathrm{~km} / \mathrm{s}, \alpha_{1}=\sqrt{ } 3 \beta_{2}, \beta_{2}=2 \alpha_{1}, \rho_{2}=2.5 \rho_{1}$, and $H=5.0 \mathrm{~km}$, where $\alpha, \beta, \rho$, and $H$ are $P$-wave velocity, $S$-wave velocity, density, and the thickness of the water layer, respectively; the subscripts 1 and 2 denote water and the solid layer, respectively. The group velocity dispersion curve of the fundamental Rayleigh wave in the structure of Press et al. (1950) indicates a local minimum at a propagation speed of $1.2 \mathrm{~km} / \mathrm{s}$ and dominant frequency of $0.1 \mathrm{~Hz}$, indicating that the wave with this speed and frequency (i.e., the Airy phase) is amplified significantly during propagation. In our 3D simulation case, we estimate a propagation speed of approximately $0.7 \mathrm{~km} / \mathrm{s}$ in the Airy phase, based on analysis of the apparent velocity of the isolated later phase at DONET stations KMB05-KMB08 and KMD13-KMD16, where the thicknesses of the accretionary prism and the seawater layer are almost constant. Figure 7 illustrates the vertical component of the synthetic waveform at these stations in order of epicentral distance, indicating propagation with an apparent velocity of $0.7 \mathrm{~km} /$ s. An Airy phase with similarly slow propagation has also been found in temporary ocean bottom observations of VLF events with source depths of 5-12 km near DONET stations (SUGIOKA et al. 2012).

Comparison of wavefields simulated using structural models with and without a seawater layer clearly illustrates the contribution of the Airy phase to the waveform. We calculate waveforms from the submarine landslide source at the stations using a 
(a) simulation 2 results (F-net land stations)

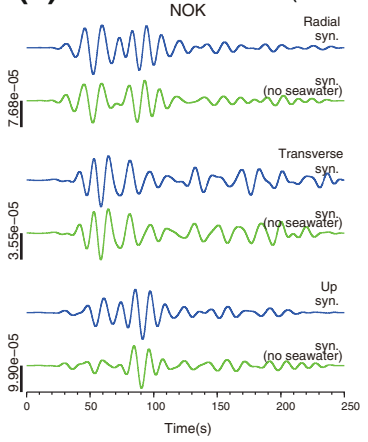

- WWWWhm

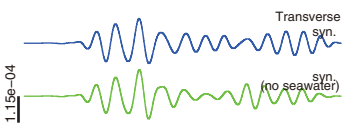

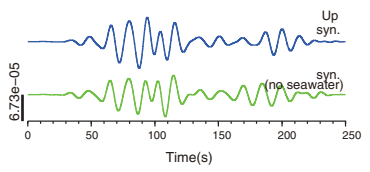

(b) simulation 2 results (DONET seafloor stations)

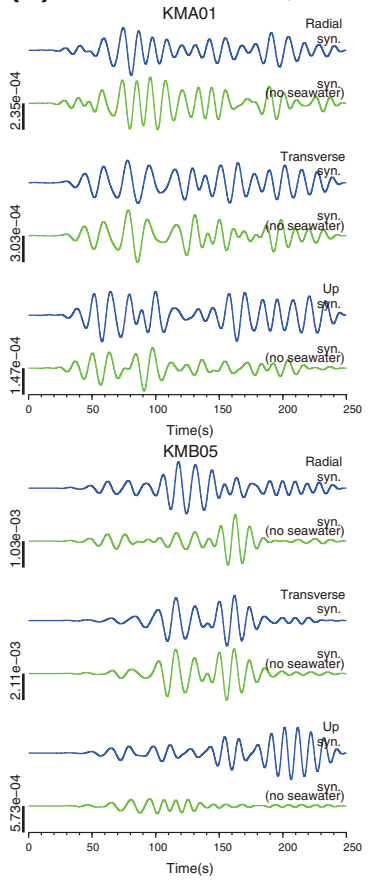

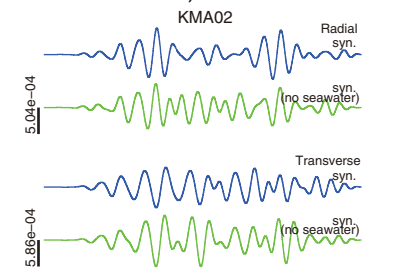
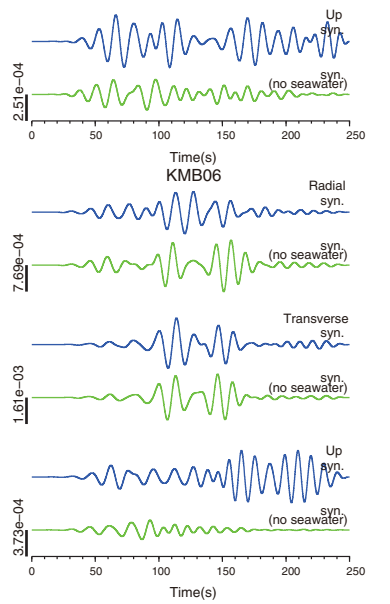

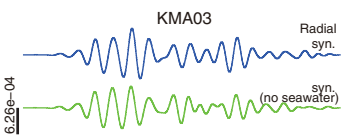
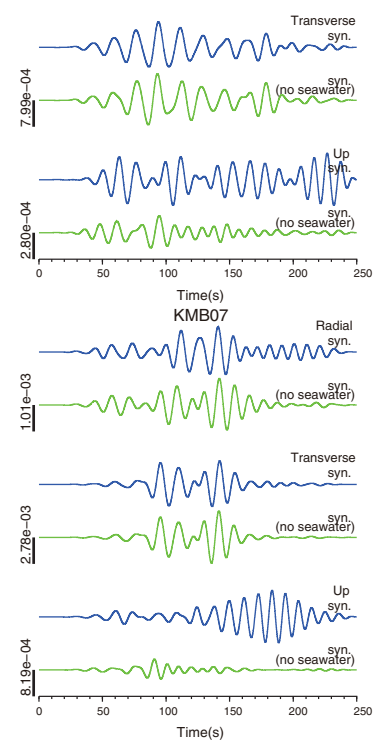
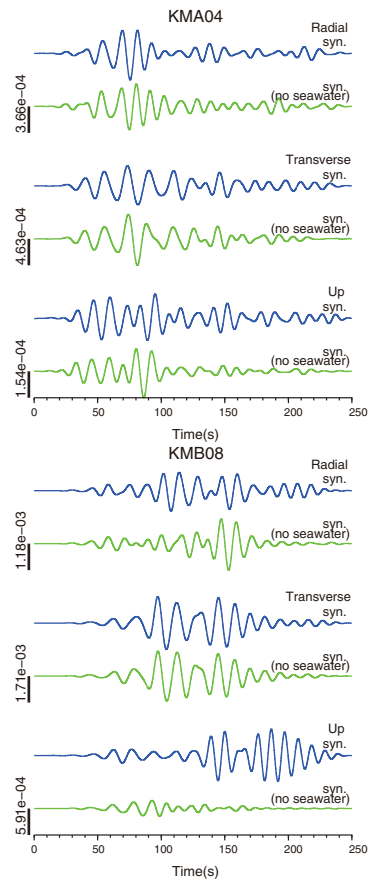

Figure 6

Simulation results for the submarine landslide source (simulation 2 in Fig. 1). Blue and green lines indicate synthetic waveforms (velocity, $\mathrm{cm} / \mathrm{s}$ ) for the structural model with and without the seawater layer, respectively. Upper, middle, and lower traces for each station represent the radial, transverse, and vertical components, respectively. a Waveforms at land stations of F-net. b Waveforms at seafloor stations of DONET. The significant waveform difference between the structural models for the vertical component is shown at the seafloor stations of DONET

structural model without a seawater layer, which we construct simply by replacing the seawater layer of the original structural model with an air layer. The green line in Fig. 6 represents the synthetic waveforms for the non-seawater structural model. For the vertical component, we find the main seismic motions to have shorter durations than those obtained for the model that includes the seawater layer (blue line). This difference in synthetic waveforms between models is almost imperceptible for the three components at the land stations and the transverse component at the seafloor stations but is considerable for the vertical component at the seafloor stations. In the case of the non-seawater model, we are unable to discern the prominent later phase corresponding to the Airy phase for the vertical component of the synthetic waveform at the DONET seafloor stations. For example, at station KMB05, the prominent later 
(b) simulation 2 results (DONET seafloor stations)

KMC09 KMC10 KMC11

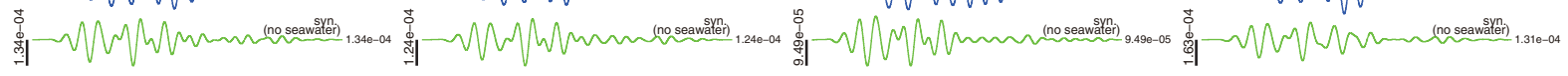
Transverse

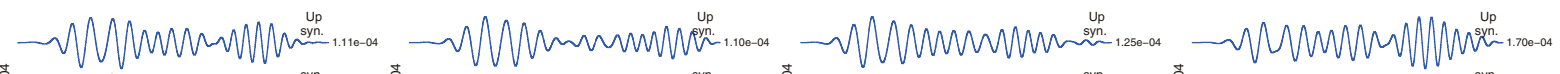

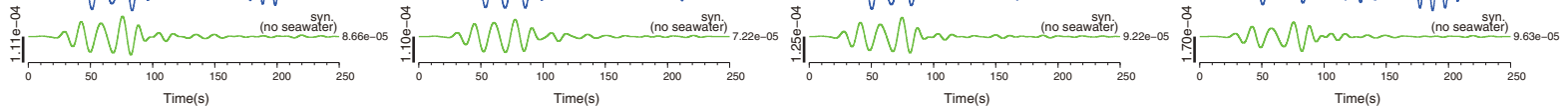
KMD13 (no seawaler) Transe

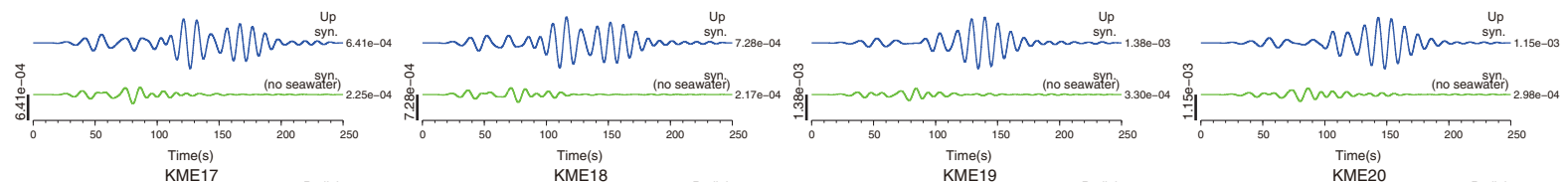
KME17

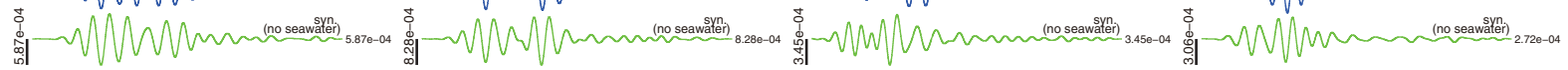
Transverse

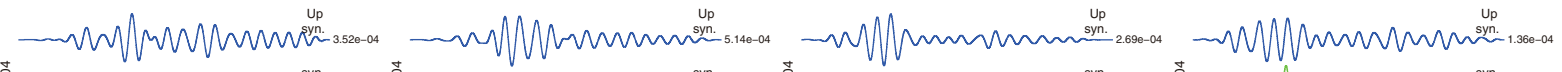

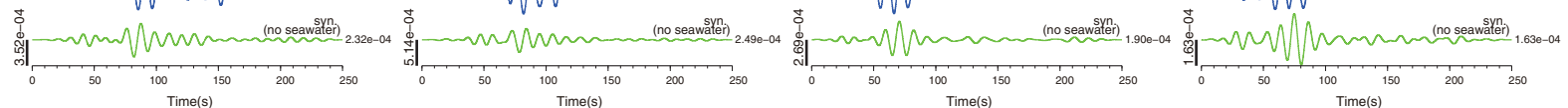

Figure 6 continued

phase cannot be seen for 150-240 s of the vertical component, in contrast to the results for the seawater model. These results indicate that the seawater layer plays an important role in amplifying the Airy phase for slow propagation speeds and contributes to the generation of a long duration composed of successive large seismic motions at the seafloor.

\subsection{Effects of Accretionary Prism and Seawater on Wavefields}

Here, we discuss the effects of the accretionary prism and the seawater layer on seismic wave propagation at the seafloor. Figure 8 illustrates snapshots at 20,80 , and $120 \mathrm{~s}$ for the vertical component of waveforms derived from the terrestrial and submarine landslide sources. The cross section of the snapshots is based on the $x-z$ plane through each source epicenter. We find that seismic energy is accumulated primarily at shallow depth around the seawater layer and the accretionary prism, whereas little energy accumulated in the deep regions and around the free surface of the land area. Such accumulation is likely due to trapping of seismic energy, which consists primarily of $S$ waves and Rayleigh waves, in the accretionary prism and the 


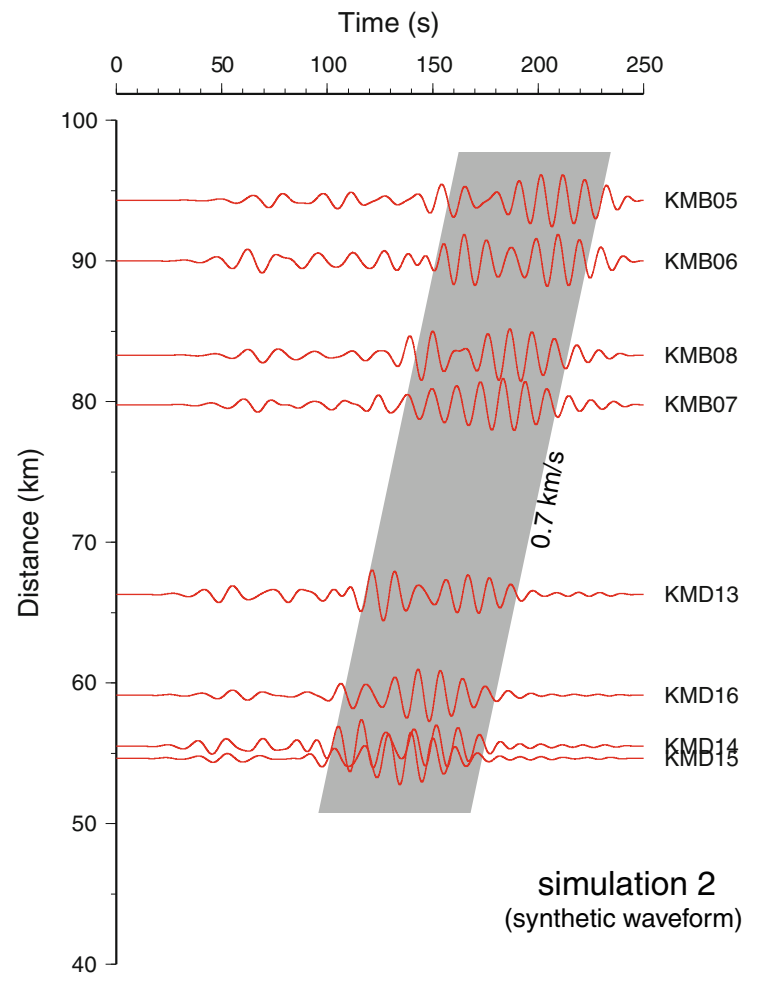

Figure 7

Vertical component of the synthetic waveform at seafloor stations KMB05-KMB08 and KMD13-KMD16 of DONET in order of epicentral distance. The propagation of the Airy phase with an apparent velocity of $0.7 \mathrm{~km} / \mathrm{s}$ is shown by a thick gray line

seawater layer. These propagation features, which are strongly dependent on the velocity structure, are responsible for the main differences in waveform amplitude and duration of seismic motion between stations. Furthermore, we have illustrated the spatial distribution of the maximum amplitude for the synthetic and observed waveforms for a given terrestrial landslide source in Fig. 5. Our results show that the maximum amplitude is relatively small and is independent of epicentral distance for stations NOK and WTR of F-net (land stations) and KMC09KMC12 of DONET (seafloor stations). This occurs because the seismic waves are trapped to a lesser degree around these stations than around other stations in the study area (see snapshots in Fig. 8). The accretionary prism extends below stations KMC09-KMC12 but forms only a thin layer, resulting in the smaller amplitude detected for these stations, particularly compared to other seafloor stations where the accretionary prism is thicker (e.g., KMB05-KMB08 and KMD13-KMD16).

We have obtained the maximum amplitude of each component at the stations for the submarine landslide source using structural models with (solid symbols) and without (open symbols) a seawater layer (Fig. 9). Our results indicate trends in amplitude distribution that are similar to those found for the terrestrial landslide source, although these trends are more pronounced for the seawater model than the non-seawater model. It should also be noted that a significant difference in amplitude is found between the seawater and non-seawater models, particularly for the vertical component; this can be attributed to the amplification of the Airy phase as described in Sect. 5.2. At station KMD15, the maximum amplitude of the vertical component of the synthetic waveform for the seawater model is four times greater than that for the non-seawater case; this implies that the amplitude of the seismic waveform in the oceanic area depends significantly on the velocity structure, particularly on the presence of the seawater layer and accretionary prism. Ignoring these characteristic structures in the oceanic area and simply calculating the Green's function using the same structural model used for land areas would result in erroneous estimation of the size of the submarine landslide and the mechanisms underlying its generation. We emphasize that it is necessary to incorporate a structural model that includes the 3D accretionary prism and seawater layer into simulations in order to precisely evaluate seismic wavefields in seafloor areas.

\section{Conclusions}

We model seismic wavefields for a terrestrial landslide source at land stations of F-net and seafloor stations of DONET around the Kii peninsula in southwest Japan using our HOT-FMD scheme for frequencies of $0.05-0.1 \mathrm{~Hz}$. Assuming the epicenter to be located in the vicinity of a large submarine slump, we also model wavefields at the same 
simulation 1 (terrestrial landslide)
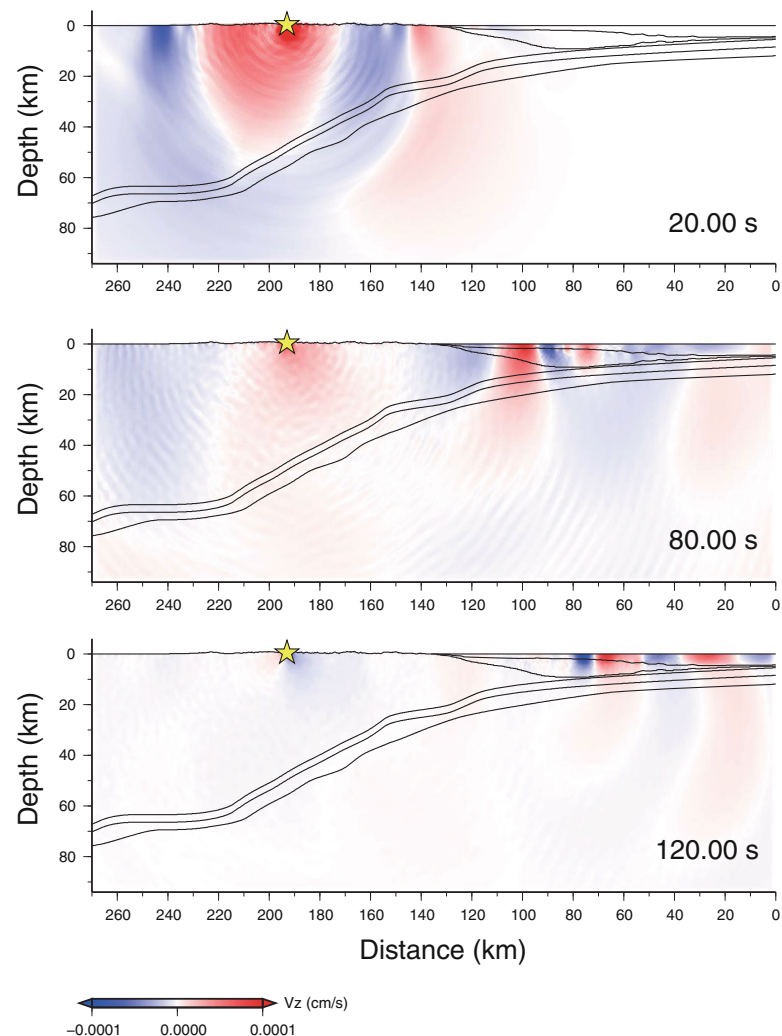

simulation 2 (submarine landslide)
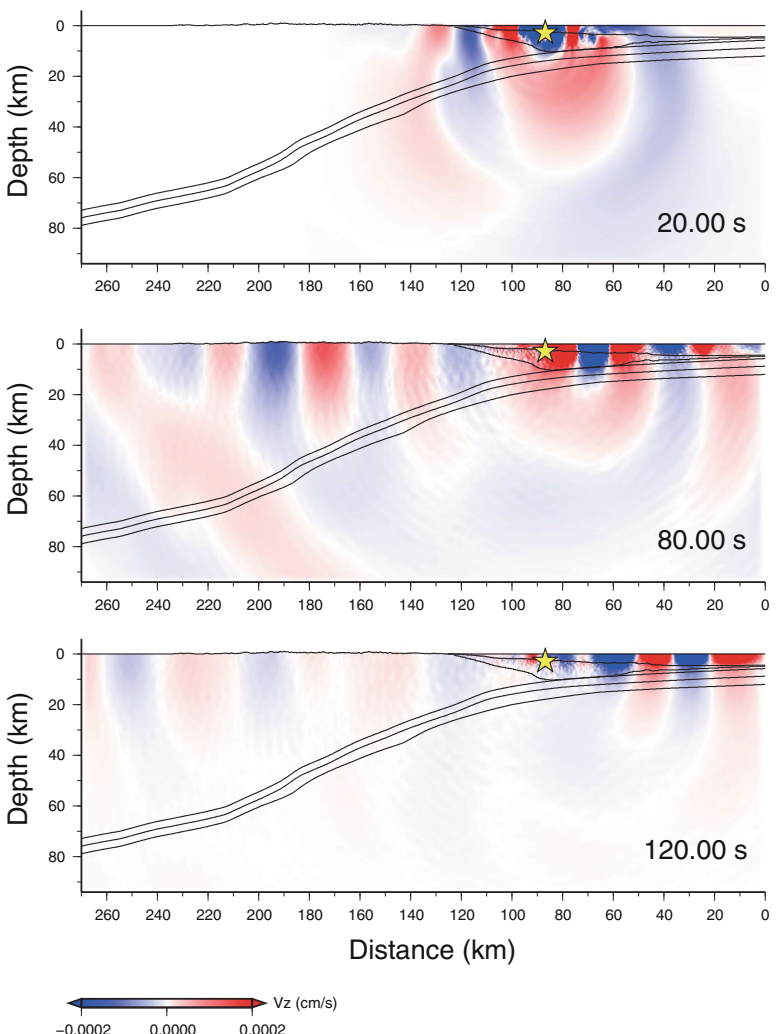

Figure 8

Snapshots of the vertical component of waveforms at 20, 80, and $120 \mathrm{~s}$. Left and right panels show the snapshots for the terrestrial (simulation 1 in Fig. 1) and submarine (simulation 2) landslide sources, respectively. The cross section of the snapshots is based on the $x-z$ plane through each source epicenter. The seismic energy with slow propagation speed accumulates primarily at shallow depths, particularly around the seawater layer and the accretionary prism, whereas little energy accumulates in the deep region and around the free surface of the land area

stations for a submarine landslide source. Our results find the propagation of the Airy phase with an apparent velocity of $0.7 \mathrm{~km} / \mathrm{s}$ to be associated with the seawater layer and the accretionary prism for the vertical component of waveforms at the seafloor stations. However, we do not witness this later phase when adopting a structural model that does not incorporate the seawater layer. We also find that the amplification of the waveform depends on both the presence of the seawater and the thickness of the accretionary prism, as indicated by the low amplitudes found at the land stations and at seafloor stations near the trough (which are located above a thin low-velocity layer) and the high amplitudes found at the other stations away from the trough (which are located above a thick layer). For the model incorporating seawater, the amplitude of the vertical component at seafloor stations KMB and KMD (which are located between the trough and the coast) can be up to four times greater than that for the model excluding seawater, likely owing to the effect of the seawater layer on the wavefields. Ignoring these characteristic structures in the oceanic area and calculating wavefields simply using the same structural model used for land areas would result in erroneous estimation of the size of the submarine landslide and the mechanisms underlying its generation. Our results highlight the importance of incorporating a structural model that includes the $3 \mathrm{D}$ accretionary prism and the seawater layer into simulations in order to precisely evaluate seismic wavefields in seafloor areas. 


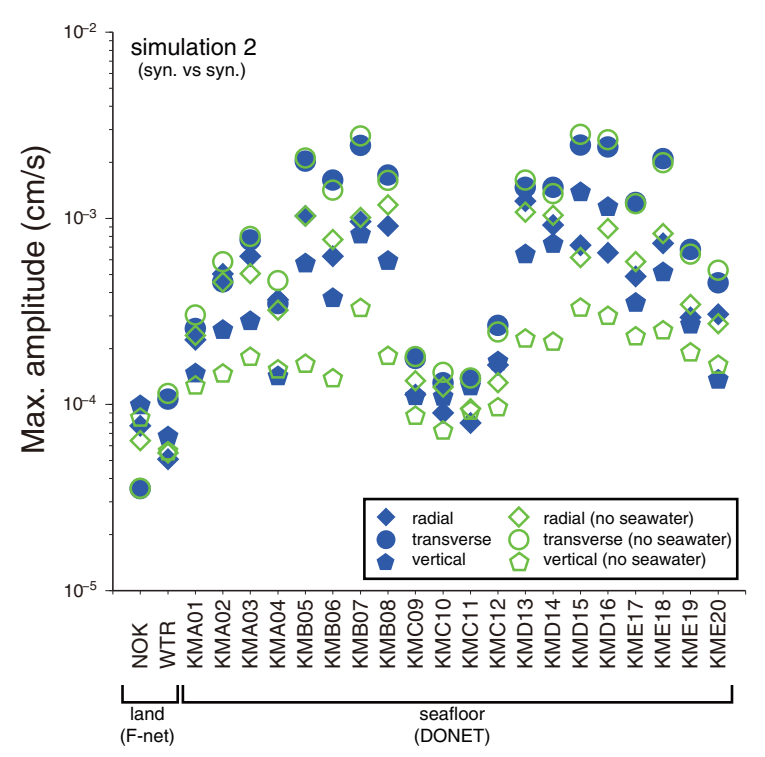

Figure 9

Maximum amplitude of each component at the stations for the submarine landslide source for models with and without a seawater layer. Open diamonds, circles, and pentagons indicate radial, transverse, and vertical components, respectively, of the synthetic waveforms for the non-seawater model. Solid diamonds, circles, and pentagons indicate radial, transverse, and vertical components, respectively, of the synthetic waveforms for the seawater model. It should be noted that the clear difference in amplitude between the seawater and non-seawater models is particularly pronounced in the vertical component at DONET seafloor stations

\section{Acknowledgments}

Discussions with Masaru Nakano and Toshitaka Baba were very fruitful. Masumi Yamada kindly provided us with data of the source time function of the 2011 landslide event. Comments from two anonymous reviewers helped to improve the manuscript. The broadband data recorded by F-net stations were obtained from the National Research Institute for Earth Science and Disaster Prevention (NIED). The 5 and $50 \mathrm{~m}$ mesh topography data were provided by the Geospatial Information Authority of Japan (GSI) and the $500 \mathrm{~m}$ mesh seafloor topography data by the Japan Oceanographic Data Center (JODC). Seafloor topography data were also provided by the Data Research System for Whole Cruise Information (DARWIN) of the Japan Agency for Marine-Earth Science and Technology (JAMSTEC). The JMA 2001 velocity model was provided by the Japan Meteorological Agency (JMA). The FDM simulations were conducted using the ICE X system of JAMSTEC. The Generic Mapping Tools package by Wessel and SMith (1998) was used to create the figures.

Open Access This article is distributed under the terms of the Creative Commons Attribution License which permits any use, distribution, and reproduction in any medium, provided the original author(s) and the source are credited.

\section{REFERENCES}

Alford, R. M., K. R. Kelly, and D. M. Boore (1974). Accuracy of finite-difference modeling of acoustic-wave equation, Geophysics 39, 834-842.

Baba, T., H. Matsumoto, K. Kashiwase, T. Hyakudome, Y. KanEDA, and M. SANO (2012). Micro-bathymetric evidence for the effect of submarine mass movement on tsunami generation during the 2009 Suruga Bay earthquake, Japan, in Advances in Natural and Technological Hazards Research 31, Springer, Dordrecht, 485-495.

Bondevik, S., F. Løvholt, C. Harbitz, J. Mangerud, A. Dawson, and J. I. SVEndSEn (2005). The Storegga Slide tsunami-comparing field observations with numerical simulations, Mar. Petrol. Geol. 22, 195-208.

BROCHER, T. A. (2005). Empirical relations between elastic wavespeeds and density in the earth's crust, Bull. Seism. Soc. Am. 95, 2081-2092.

Chen, C. H., W. A. Chao, Y. M. Wu, L. Zhao, Y. G. Chen, W. Y. Ho, T. L. Lin, K. H. Kuo, and J. M. Chang (2013). A seismological study of landquakes using a real-time broad-band seismic network, Geophys. J. Int. 194, 885-898.

Chigira, M., Y. Matsushi, C. Y. Tsou, N. Hiraishi, M. Matsuzawa, and S. Matsuura (2012). Deep-seated catastrophic landslides induced by Typhoon 1112 Talas, Annu. Disas. Prev. Res. Inst., Kyoto Univ. 55, 193-211.

CitaK, S. O., T. Nakamura, A. Nakanishi, Y. Yamamoto, M. OHori, T. BABA, and Y. KANEDA (2012). An updated model of three-dimensional seismic structure in the source area of the Tokai-Tonankai-Nankai earthquake, Abstr. Asia Oceania Geosci. Soc. 2012, Singapore, 13-17 August 2012, OS06-A015.

Dahlen, F. A. (1993). Single-force representation of shallow landslide sources, Bull. Seism. Soc. Am. 83, 130-143.

Drossaert, F. H. and A. Giannopoulos (2007). Complex frequency shifted convolution PML for FDTD modelling of elastic waves, Wave Motion 44, 593-604.

EISSLER, H. K. and H. KANAMORI (1987). A single force model for the 1975 Kalapana, Hawaii, earthquake, J. Geophys. Res. 92, 4827-4836.

Fujiwara, T., S. Kodaira, T. No, Y. Kaiho, N. TaKahashi, and Y. KANEDA (2011). The 2011 Tohoku-Oki earthquake: Displacement reaching the trench axis, Science 334, 1240.

FuKaO, Y. (1995). Single-force representation of earthquakes due to landslides or the collapse of caverns, Geophys.J. Int. 122, 243-248.

Guzzetti, F., B. D. Malamud, D. L. Turcotte, and P. Reichenbach (2002). Power-law correlations of landslide areas in central Italy, Earth Planet. Sci. Lett. 195, 169-183. 
Hasegawa, H. S. and H. Kanamori (1987). Source mechanism of the magnitude 7.2 Grand-Banks Earthquake of November 1929: Double couple or submarine landslide, Bull. Seism. Soc. Am. 77, 1984-2004.

HeEzen B. C. and M. Ewing (1952). Turbidity currents and submarine slumps, and the 1929 Grand Banks Earthquake, Am. J. Sci. 250, 849-873.

Heinrich, P., A. Piatanesi, and H. Hébert (2001). Numerical modelling of tsunami generation and propagation from submarine slumps: the 1998 Papua New Guinea event, Geophys. J. Int. $145,97-111$.

Kanamori, H. (1972). Mechanism of tsunami earthquakes, Phys. Earth Planet. Inter. 6, 346-359.

Kanamori, H. and J. W. Given (1982). Analysis of long-period seismic-waves excited by the May 18, 1980, eruption of Mount St Helens-A terrestrial monopole, J. Geophys. Res. 87, 5422-5432.

Kaneda Y., K. Kawaguchi, E. Araki, H. Matsumoto, A. Sakuma, T. Nakamura, S. Kamiya, K. Ariyoshi, T. Baba, M. Ohori, and T. Hori (2010). Development of real time monitoring system (DONET) for understanding mega thrust, Abstr. Japan Geoscience Union Meet. 2010, Makuhari, 23-28 May 2010, SSS027P25.

KaWAGUChI, K., E. ARAKI, and Y. Kaneda (2011). Establishment of a method for real-time and long-term seafloor monitoring, J. Adv. Mar. Sci. Tech. Soc. 17, 125-135 (in Japanese).

Kawamura, K., T. Sasaki, T. Kanamatsu, A. Sakaguchi, and Y. OGawa (2012). Large submarine landslides in the Japan Trench: A new scenario for additional tsunami generation, Geophys. Res. Lett. 39, L05308, doi:10.1029/2012GL050661.

La Rocca, M., D. Galluzzo, G. Saccorotti, S. Tinti, G. B. Cimini, and E. Del Pezzo (2004). Seismic signals associated with landslides and with a tsunami at Stromboli volcano, Italy, Bull. Seism. Soc. Am. 94, 1850-1867.

Lin, C. H., H. Kumagai, M. Ando, and T. C. Shin (2010). Detection of landslides and submarine slumps using broadband seismic networks, Geophys. Res. Lett. 37, L22309, doi:10.1029/ 2010GL044685.

Moczo, P., J. KRIstek, and L. Halada (2000). 3D fourth-order staggered-grid finite-difference schemes: Stability and grid dispersion, Bull. Seism. Soc. Am. 90, 587-603.

Nakamura, T., H. Takenaka, T. Окамоto, and Y. Kaneda (2011). A study of the finite difference solution for $3 D$ seismic wavefields near a fluid-solid interface, Zisin 2 (J. Seism. Soc. Jpn.) 63, 187-194 (in Japanese).

NAKAMURA, T., H. TAKenaKa, T. OKamoto, and Y. KANEDA (2012). FDM simulation of seismic-wave propagation for an aftershock of the 2009 Suruga Bay earthquake: Effects of ocean-bottom topography and seawater layer, Bull. Seism. Soc. Am. 102, 2420-2435.

Nakanishi, A., N. Takahashi, J. O. Park, S. Miura, S. Kodaira, Y. Kaneda, N. Hirata, T. Iwasaki, and M. Nakamura (2002). Crustal structure across the coseismic rupture zone of the 1944 Tonankai earthquake, the central Nankai Trough seismogenic zone, J. Geophys. Res. 107, doi:10.1029/2001JB000424.
Nakano, M., T. Tonegawa, and Y. Kaneda (2012). Orientations of DONET seismometers estimated from seismic waveforms, JAMSTEC Rep. Res. Dev. 15, 77-89 (in Japanese with English abstract).

Окамото, T. and H. TAKenaKa (2005). Fluid-solid boundary implementation in the velocity-stress finite-difference method, Zisin 2 (J. Seism. Soc. Jpn.) 57, 355-364 (in Japanese with English abstract).

Pekeris, C. L. (1948). Theory of propagation of explosive sound in shallow water, in Propagation of Sound in the Ocean, Geol. Soc. Am., New York.

Press, F, M. Ewing, and I. Tolstoy (1950). The Airy phase of shallow-focus submarine earthquakes, Bull. Seism. Soc. Am. 40, 111-148.

Shiomi, K., H. Sato, K. Obara, and M. Ohtake (2004). Configuration of subducting Philippine Sea plate beneath southwest Japan revealed from receiver function analysis based on the multivariate autoregressive model, J. Geophys. Res. 109, B04308, doi:10.1029/2003JB002774.

Sugioka, H., T. OKamoto, T. Nakamura, Y. Ishihara, A. Ito, K. Obana, M. Kinoshita, K. Nakahigashi, M. Shinohara, and Y. FUKAO (2012). Tsunamigenic potential of the shallow subduction plate boundary inferred from slow seismic slip, Nature Geosci. 5, 414-418.

TAKenaka, H., T. Nakamura, T. OKamoto, and Y. Kaneda (2009). A unified approach implementing land and ocean-bottom topographies in the staggered-grid finite-difference method for seismic wave modeling, Proc. 9th SEGJ Int. Symp., Sapporo, 12-14 October 2009, doi:10.1190/SEGJ092009-001.13.

Tappin, D. R., P. Watts, G. M. McMurtry, Y. Lafoy, and T. Matsumoto (2001). The Sissano, Papua New Guinea tsunami of July 1998 -offshore evidence on the source mechanism, Marine Geology 175, 1-23.

Ueno, H., S. Hatakeyama, T. Aketagawa, J. Funasaki, and N. HAMADA (2002). Improvement of hypocenter determination procedures in the Japan Meteorological Agency, Quart. J. Seism. 65, 123-134 (in Japanese with English abstract).

WARD, S. N. (2001). Landslide tsunami, J. Geophys. Res. 106, $11201-11215$.

WeBB, S. C. (1998). Broadband seismology and noise under the ocean, Rev. Geophys. 36, 105-142.

Wessel, P. and W. H. F. Sмith (1998). New, improved version of Generic Mapping Tools released, Eos Trans. AGU 79, 579.

YAmada, M., Y. Matsushi, M. ChigiRA, and J. Mori (2012). Seismic recordings of landslides caused by Typhoon Talas (2011), Japan, Geophys. Res. Lett. 39, L13301, doi:10.1029/2012GL052174.

Yamada, M., H. Kumagai, Y. Matsushi, and T. MatsuZawa (2013). Dynamic landslide processes revealed by broadband seismic records, Geophys. Res. Lett. 40, 2998-3002, doi:10.1002/GRL. 50437.

Yang, Z., A. F. Sheehan, J. A. Collins, and G. Laske (2012). The character of seafloor ambient noise recorded offshore New Zealand: Results from the MOANA ocean bottom seismic experiment, Geochem. Geophys. Geosys. 13, Q10011, doi:10. 1029/2012GC004201. 